\title{
Iron-enhanced coagulation is attenuated by chelation: a thrombelastographic and ultrastructural analysis
}

\author{
Vance G. Nielsen ${ }^{\mathrm{a}}$ and Etheresia Pretorius ${ }^{\mathrm{b}}$
}

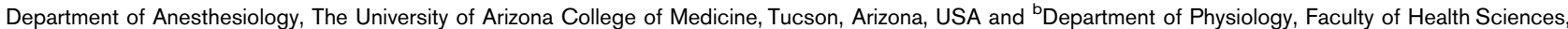 \\ University of Pretoria, Arcadia, South Africa \\ Correspondence to Vance G. Nielsen, MD., Department of Anesthesiology, The University of Arizona College of Medicine, P.O. Box 245114, 1501 North Campbell \\ Avenue, Tucson, Arizona 85724-5114, USA \\ Tel: +1 520 626-7195; fax: +1 520 626-6943; e-mail: vgnielsen333@gmail.com
}

Increased circulating ferritin and free iron have been found in a variety of disease states associated with thrombophilia. When blood or plasma is exposed to iron addition, characteristic changes in thrombus formation are observed by scanning electron microscopy, which include fusion of fibrin polymers, matting, and even sheeting of fibrin.

A primary mechanism posited to explain iron-mediated hypercoagulability is hydroxyl radical formation and modification of fibrinogen; however, iron has also been demonstrated to bind to fibrinogen. We have recently demonstrated that iron enhances coagulation, manifested as a decrease in the time of onset of coagulation. Using clinically encountered concentrations of iron created by addition of $\mathrm{FeCl}_{3}$ to human plasma, we demonstrated that iron-mediated changes in reaction time determined by thrombelastography or changes in thrombus ultrastructure were significantly, but not completely, reversed by iron chelation with deferoxamine. Thus, reversible iron binding to fibrinogen mechanistically explains a significant portion of coagulation kinetic and ultrastructural hypercoagulability. Further investigation is needed to determine whether residual iron binding or other iron-mediated effects is responsible for hypercoagulability observed after chelation.

Keywords: coagulation, electron microscopy, iron, thrombelastography

\section{Introduction}

As has been recently reviewed [1], increased circulating ferritin and free iron have been found in a variety of disease states associated with thrombophilia. When blood or plasma is exposed to iron addition, characteristic changes in thrombus formation are observed, which include fusion of fibrin polymers, matting, and even sheeting of fibrin [1-6]. This scanning electron micrographic (SEM) signature has also been documented in thrombi obtained from patients with diseases involving chronic iron overload $[1,2,7,8]$. It has been posited that iron-derived hydroxyl radicals interact with fibrinogen, resulting in hypercoagulation and hypofibrinolysis $[1,3,9,10]$. Of interest, exposing plasma to iron chelators such as deferoxamine or antioxidants significantly attenuated ultrastructural change in clots exposed to exogenous iron [11]. Further, plasma obtained from patients with hemochromatosis or chronic hyperferritinemia demonstrated a SEM signature similar to that of iron exposure that was attenuated by deferoxamine [12]. In sum, although not directly demonstrated, it appeared that iron-fibrinogen interactions resulted in characteristic clot ultrastructure similar to that of diseases with chronic iron overload and thrombophilia.

On the contrary, the concept that iron-modified fibrinogen via hydroxyl radical exposure is not supported by the observation that the procoagulant properties of fibrinogen are compromised by essentially all radical species tested by other investigators $[13,14]$. Indeed, given the concentration of antioxidants present in plasma $(>1600 \mu \mathrm{mol} / \mathrm{l})$ [15], it is unlikely that the addition of $6-30 \mu \mathrm{mol} / \mathrm{l}$ ferric chloride could generate hydroxyl radicals that exclusively affect fibrinogen. Instead, it appeared that iron directly bound to fibrinogen in a recent study [16]. Thus, it seems more plausible that iron-fibrinogen binding and potential fibrinogen conformational change may enhance coagulation. Iron-mediated phenomenon may be similar to that observed with enhancement of fibrinogen after carbon monoxide exposure [17]. Thus, modulation of the effects of iron on coagulation with chelation would speak strongly for an important role of iron-binding rather than only radical damage.

Although the precise molecular mechanism by which iron affects fibrinogen remained to be elucidated, we recently published an investigation of the effects of a small concentration $(10 \mu \mathrm{mol} / \mathrm{l})$ of ferric chloride on coagulation and fibrinolysis [18]. We found that the thrombelastographic, kinetic sine quo non of iron was a decrease in the onset time of coagulation and an increase in the velocity of thrombus growth [18]. The SEM signature of thrombi exposed to this small concentration of iron [18] demonstrated the typical changes previously mentioned [1-6]. Thus, the purpose of this study was to evaluate the effects of deferoxamine-mediated chelation on ironexposed plasma with thrombelastographic and SEMbased analyses. 


\section{Methods}

\section{Thrombelastograph-based analyses}

All thrombelastograph-based experiments were performed at the University of Arizona. Frozen, citrate anticoagulated normal pooled plasma was obtained from a commercial vendor (George King Bio-Medical, Overland Park, Kansas, USA) for use in subsequently described experimentation. With regard to chemicals utilized, ferric chloride $\left(\mathrm{FeCl}_{3}, 99.9 \%\right.$ pure $)$ and calcium-free phosphate-buffered saline (PBS) were obtained from a commercial vendor (Sigma-Aldrich, Saint Louis, Missouri, USA). Deferoxamine was obtained from a commercial vendor (Cayman Chemical Company, Ann Arbor, Michigan, USA).

First, a concentration-response relationship of iron concentration and reaction time $(\mathrm{R}$, defined as $2 \mathrm{~mm}$ clot strength; this is also known as clotting time in thromboelastometric analyses) was determined. The rationale for using $\mathrm{R}$ time was that it is the first indication of the onset of coagulation, is used in both thrombelastographic and thromboelastometric systems, and is anticipated to quickly and easily detect iron-mediated enhancement of coagulation based on our previous work under review. This concentration-response relationship was generated with a ROTEM delta hemostasis system (Tem Innovations $\mathrm{GmbH}$, Munich, Germany) generously provided by the manufacturer. All disposable cups/pins and reagents were also provided by Tem Innovations. Plasma was rapidly thawed at $37^{\circ} \mathrm{C}$ on the day of experimentation. Separate aliquots of plasma were exposed to $1 \%$ $\mathrm{v} / \mathrm{v}$ additions of ferric chloride dissolved in PBS that resulted in final concentrations of $0-10 \mu \mathrm{mol} / 1 \quad(n=5-6$ replicates per concentration). After $3 \mathrm{~min}$ or more of incubation at room temperature, $320 \mu$ of these ironexposed plasmas was subsequently placed in a disposable cup, with subsequent addition of $20 \mu \mathrm{l}$ of $200 \mathrm{mmol} / \mathrm{l}$ $\mathrm{CaCl}_{2}$. The complete sample was mixed by pipette once, and the reaction commenced at $37^{\circ} \mathrm{C}$. The $\mathrm{R}$ values were subsequently recorded.

The second series of experiments examined the role of time on chelation of iron from plasma and consequent changes in R. First, plasma that was rapidly thawed at $37^{\circ} \mathrm{C}$ on the day of experimentation was exposed to either a $1 \%$ $\mathrm{v} / \mathrm{v}$ addition of $\mathrm{PBS}$ or $\mathrm{FeCl}_{3}(10 \mu \mathrm{mol} / \mathrm{l}$ final concentration) for $3 \mathrm{~min}$. Then, $336 \mu \mathrm{l}$ of either plasma mixture was placed in a disposable cup in a computer-controlled thrombelastograph hemostasis system (Model 5000; Haemoscope Corp., Niles, Illinois, USA). An addition of $3.6 \mu \mathrm{l}$ deferoxamine in $\mathrm{dH}_{2} \mathrm{O}$ ( 0 or $1 \mathrm{mmol} / \mathrm{l}$ final concentration) was added to the plasma mixture, mixed with the disposable pin, and allowed to incubate for $3 \mathrm{~min}$ at $37^{\circ} \mathrm{C}$. Thus, there were four conditions: no deferoxamine, no $\mathrm{FeCl}_{3}$, (Control), deferoxamine, no $\mathrm{FeCl}_{3}$ (Deferoxamine); no deferoxamine, $\mathrm{FeCl}_{3}\left(\mathrm{FeCl}_{3}\right)$; and finally, $\mathrm{FeCl}_{3}$ followed by deferoxamine $\left(\mathrm{FeCl}_{3}+\right.$ Deferoxamine $)$. Thereafter, $20 \mu \mathrm{l}$ of $200 \mathrm{mmol} / \mathrm{l} \mathrm{CaCl}_{2}$ was added as the last step to initiate clotting. Data were collected at $37^{\circ} \mathrm{C}$ for until $\mathrm{R}$ was recorded. In the next set of this experimental series, an identical addition of PBS or $\mathrm{FeCl}_{3}$ to plasma was performed with a 3 -min incubation, followed by a $1 \% \mathrm{v} / \mathrm{v}$ of deferoxamine ( 0 or $1 \mathrm{mmol} / \mathrm{l}$ final concentration), with this plasma kept in a sealed tube at room temperature for approximately $40 \mathrm{~min}$. An aliquot of $340 \mu \mathrm{l}$ of each of the four conditions was placed into thrombelastographic cups and $20 \mu \mathrm{l}$ of $200 \mathrm{mmol} / \mathrm{l} \mathrm{CaCl}_{2}$ was added to initiate clotting. Data were collected at $37^{\circ} \mathrm{C}$ until $\mathrm{R}$ was recorded. There were six replicates per condition for all conditions in these series of experiments. As $\mathrm{R}$ values varied between experiments, and a fixed number of channels were available $(n=4)$, plasma incubated at room temperature between 45 and 60 min prior to initiation of coagulation.

The third series of experiments was designed to decrease incubation time by increasing temperature and deferoxamine concentration without compromising the ability to detect iron-mediated changes in $\mathrm{R}$ values. In these experiments, plasma had a $1 \% \mathrm{v} / \mathrm{v}$ addition of PBS or $\mathrm{FeCl}_{3}(10 \mu \mathrm{mol} / \mathrm{l}$ final concentration $)$ followed by a $3 \mathrm{~min}$ incubation at room temperature. Subsequently, $330 \mu \mathrm{l}$ of either of these plasma types was placed in disposable thrombelastograph cups, with addition of $\mathrm{dH}_{2} \mathrm{O}$ or deferoxamine $(2.78 \mathrm{mmol} / \mathrm{l}$ final concentration). The mixtures were mixed with the disposable pin and allowed to incubate for $15 \mathrm{~min}$ at $37^{\circ} \mathrm{C}$. Clotting was initiated with $20 \mu \mathrm{l}$ of $\mathrm{CaCl}_{2}$ and data were collected at $37^{\circ} \mathrm{C}$ until $\mathrm{R}$ was recorded. Six replicates of the four conditions were analyzed.

\section{Scanning electron micrographic-based analyses}

All SEM-based analyses were conducted at the University of Pretoria. For the SEM experiments, $80 \mathrm{ml}$ of whole blood was collected from a single donor, and anticoagulated with sodium citrate (nine parts blood to one part $0.105 \mathrm{~mol} / \mathrm{l}$ sodium citrate), and platelet-rich plasma (') was obtained from each collected sample by centrifuging the whole blood at $1250 \mathrm{~g}$ for $2 \mathrm{~min}$. The donor was a healthy, nonsmoking female individual (age: 45; serum ferritin level: $13 \mathrm{ng} / \mathrm{ml}$; and percentage of iron saturation: $22 \%)$.

In the SEM experiments, six different combinations of products and incubation times were prepared. Combination 1 (C1) consisted of $1 \mathrm{ml}$ of PRP mixed with $10 \mu \mathrm{l}$ of PBS and $10 \mu \mathrm{l}$ of double-distilled water. Combination 2 (C2) consisted of $1 \mathrm{ml}$ of PRP mixed with $10 \mu \mathrm{PBS}$ and $10 \mu \mathrm{l}$ of $100 \mathrm{mmol} / \mathrm{l}$ deferoxamine, followed by incubation for $3 \mathrm{~min}$ at room temperature. Combination 3 (C3) consisted of $1 \mathrm{ml}$ PRP mixed with $10 \mu \mathrm{l}$ of $1 \mathrm{mmol} / \mathrm{l}$ $\mathrm{FeCl}_{3}$, followed by incubation at room temperature for 3 min. Combination 4 (C4) consisted of $1 \mathrm{ml}$ PRP mixed with $10 \mu \mathrm{l}$ of $1 \mathrm{mmol} / \mathrm{l} \mathrm{FeCl}_{3}$, followed by incubation at room temperature for $3 \mathrm{~min} ; 10 \mu \mathrm{l}$ of $100 \mathrm{mmol} / \mathrm{l} \mathrm{defer-}$ oxamine was then added. Combination 5 (C5) consisted of $1 \mathrm{ml} \mathrm{PRP}$ mixed with $10 \mu \mathrm{l}$ of $1 \mathrm{mmol}^{\mathrm{m}} \mathrm{FeCl}_{3}$ and $10 \mu \mathrm{l}$ 
of double-distilled water. This mixture was incubated at room temperature for $1 \mathrm{~h}$. Combination 6 (C6) consisted of $1 \mathrm{ml}$ PRP mixed with $10 \mu \mathrm{l}$ of $1 \mathrm{mmol} / 1 \mathrm{FeCl}_{3}$, followed by incubation at room temperature for $3 \mathrm{~min}$, followed by addition of $10 \mu \mathrm{l}$ of $100 \mathrm{mmol} / \mathrm{l}$ deferoxamine. This sample was incubated for $1 \mathrm{~h}$ at room temperature. After the aforementioned specified incubation period, $10 \mu \mathrm{l}$ of each combination (C1-C6) was added to $5 \mu$ l of thrombin, mixed on a glass cover slip, and then incubated at $37^{\circ} \mathrm{C}$ for $3 \mathrm{~min}$ before further SEM analysis preparation.

SEM preparation involved a washing of C1-C6 in $0.075 \mathrm{~mol} / \mathrm{l} \mathrm{PBS}$ for $20 \mathrm{~min}$ to remove any plasma and product residues, followed by fixing in $4 \%$ formaldehyde in for $30 \mathrm{~min}$, followed by three washing steps in $0.075 \mathrm{~mol} / \mathrm{l} \mathrm{PBS}$ for $3 \mathrm{~min}$ to remove any residual fixative. The smears were then postfixated for 15 min with $1 \%$ osmium tetroxide $\left(\mathrm{OsO}_{4}\right)$, followed by a washing process, for $3 \mathrm{~min}$ in $0.075 \mathrm{~mol} / \mathrm{l} \mathrm{PBS}$. The samples were finally dehydrated serially in $30,50,70,90 \%$, and then three times in $100 \%$ ethanol followed by drying using hexamethyldisilazane, and then mounting and coating with carbon. Once the samples had been coated, they were examined using a SEM (Zeiss ULTRA plus FEG SEM; Carl Zeiss Microscopy GmbH, Jena, Germany). The Institutional Review Board of the University of Pretoria granted approval for healthy individuals for SEM-based investigations [ethics number 151/2006 (E Pretorius) that is extended until end of 2014].

\section{Statistical analyses and graphics}

$\mathrm{R}$ data are presented as mean \pm standard deviation, with analyses conducted with a commercially available statistical program (SigmaStat 3.1; Systat Software, Inc, San Jose, California, USA). Graphics were generated with a commercially available program (OrigenPro 7.5; OrigenLab Corporation, Northampton, Massachusetts, USA). The analysis of the effects of increasing the concentration of $\mathrm{FeCl}_{3}$ on $\mathrm{R}$ values was conducted with one-way analysis of variance with the Holm-Sidak post-hoc test. As the subsequent data generated in thrombelastographic experiments violated assumptions of normality and variance, these analyses of the effects of $\mathrm{FeCl}_{3}$ and deferoxamine on $\mathrm{R}$ values were conducted with Kruskal-Wallis one-way analysis of variance with the Student-Newman-Keuls post-hoc test. A $P$ value of less than 0.05 was considered significant. Micrographs of SEM data were generated with Adobe Photoshop CS6 (Adobe Systems Inc., San Jose, California, USA).

\section{Results}

\section{Thrombelastographic data}

Data from the various series of experiments are displayed in Fig. 1 and Table 1. As seen in Fig. 1, the addition of $2-10 \mu \mathrm{mol} / 1 \mathrm{FeCl}_{3}$ to plasma resulted in significantly smaller $\mathrm{R}$ values than plasma without $\mathrm{FeCl}_{3}$ addition. Only samples exposed to $10 \mu \mathrm{mol} / \mathrm{l} \mathrm{FeCl}_{3}$ had $\mathrm{R}$ values
Fig. 1

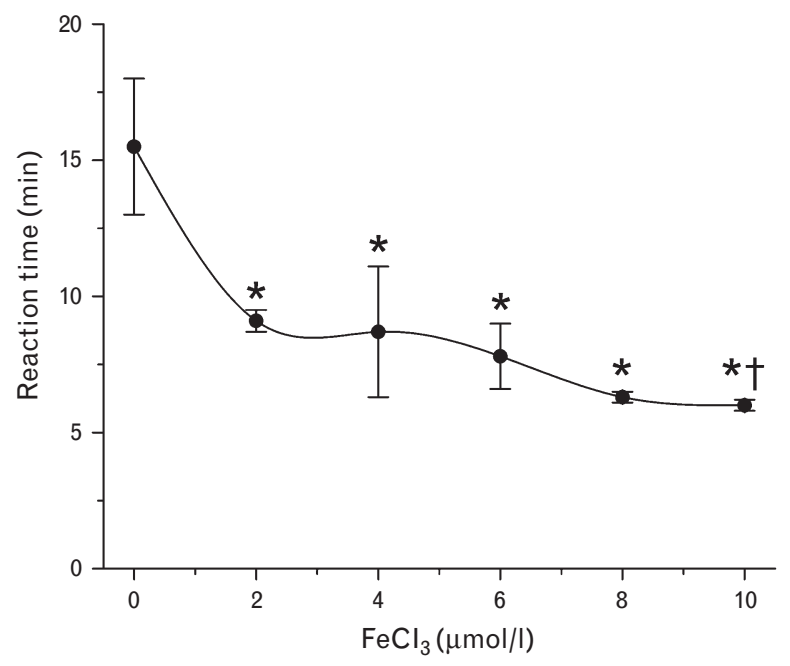

Effects of $\mathrm{FeCl}_{3}$ concentration on reaction time in normal plasma. Data presented as mean \pm standard deviation. ${ }^{*} P<0.05$ vs. $0 \mu \mathrm{mol} / \mathrm{l}$, ${ }^{\top} P<0.05$ vs. $2 \mu \mathrm{mol} / \mathrm{l}$.

significantly smaller than those exposed to $2 \mu \mathrm{mol} / \mathrm{l}$ $\mathrm{FeCl}_{3}$. The degree of reduction in $\mathrm{R}$ values by addition of $\mathrm{FeCl}_{3}$ varied by $39-61 \%$ of values observed in samples not exposed to $\mathrm{FeCl}_{3}$.

The results concerning the effects of chelation on $\mathrm{R}$ values are depicted in Table 1. Exposure to deferoxamine for 3 min resulted in a small but significant decrease in $\mathrm{R}$ values compared with control plasma values. Exposure to $\mathrm{FeCl}_{3}$ resulted in a significant $54 \%$ reduction in $\mathrm{R}$ values compared with control plasma values. This significant, $\mathrm{FeCl}_{3}$-mediated decrease in $\mathrm{R}$ values did not significantly change when deferoxamine was added for an additional $3 \mathrm{~min}$ incubation. However, after a 45-60 $\mathrm{min}$ incubation, the significant, $\mathrm{FeCl}_{3}$-mediated (72\%) decrease in $\mathrm{R}$ values was significantly attenuated by addition of deferoxamine. Compared with samples with $\mathrm{FeCl}_{3}$ addition alone, samples incubated with deferoxamine for 45-60 min after $\mathrm{FeCl}_{3}$ addition had a $108 \%$ increase in $\mathrm{R}$ values. This pattern of successful chelation of iron by deferoxamine and partial restoration of $\mathrm{R}$ values toward that of control plasma was observed in plasma incubated at $37^{\circ} \mathrm{C}$ for $15 \mathrm{~min}$ following addition of $2.78 \mathrm{mmol} / \mathrm{l}$ deferoxamine.

\section{Scanning electron micrographic data}

Figures 2 and 3 shows a low $(40000 \times$ machine magnification) and higher SEM magnification (100000× machine magnification), respectively, of the fibrin fibers created with the addition of thrombin. During fibrin formation, wherein thrombin is added to PRP, a fibrin net is formed with mainly thick, major fibers (Figs 2a and $3 a$, white arrow). When deferoxamine is added to PRP and a net is created with thrombin, the fibers do not differ 
Table 1 Effects of $\mathrm{FeCl}_{3}$ and deferoxamine on reaction time (min)

\begin{tabular}{|c|c|c|c|}
\hline Control & Deferoxamine & $\mathrm{FeCl} 3$ & $\mathrm{FeCl} 3$ + deferoxamine \\
\hline \multicolumn{4}{|c|}{ Three-minute incubation at room temperature, deferoxamine $1 \mathrm{mmol} / \mathrm{l}$} \\
\hline $13.4(12.7,14.4)$ & $11.6(11.2,12.1)^{\mathrm{a}}$ & $5.9(5.8,6.4)^{\mathrm{a}, \mathrm{b}}$ & $6.2(4.9,6.3)^{\mathrm{a}, \mathrm{b}}$ \\
\hline \multicolumn{4}{|c|}{ Forty-five to 60 -min incubation at room temperature, deferoxamine $1 \mathrm{mmol} / \mathrm{l}$} \\
\hline $17.9(15.2,20.4)$ & $17.4(16.2,18.6)$ & $5.0(4.9,5.1)^{\mathrm{a}, \mathrm{b}}$ & $10.4(9.5,11.0)^{\mathrm{a}, \mathrm{b}, \mathrm{c}}$ \\
\hline \multicolumn{4}{|c|}{ Fifteen-minute incubation at $37^{\circ} \mathrm{C}$, deferoxamine $2.78 \mathrm{mmol} / \mathrm{l}$} \\
\hline $18.8(14.0,29.1)$ & $16.2(13.1,19.7)$ & $4.6(4.4,6.0)^{\mathrm{a}, \mathrm{b}}$ & $9.2(9.0,9.4)^{\mathrm{a}, \mathrm{c}}$ \\
\hline
\end{tabular}

$\mathrm{FeCl}_{3}$ final concentration was $10 \mu \mathrm{mol} / \mathrm{l}$ in all conditions where present. Data are presented as median $\left(1^{\text {st }}, 3^{\text {rd }}\right.$ quartile). ${ }^{a} P<0.05$ vs. control ${ }^{\mathrm{b}} P<0.05$ vs. deferoxamine ${ }^{\mathrm{c}} \mathrm{P}<0.05$ vs. $\mathrm{FeCl}_{3}$.

significantly visually between healthy fiber net and the addition of the iron chelator (Figs $2 b$ and $3 b$ ).

With the addition of iron to PRP and net creation with thrombin, we have previously reported a changed fibrin fiber formation, wherein the fibers do not form individual recognizable entities. Addition of iron causes the fibers to form plates (Fig. 2c, star) and areas showing a dense fine net, and higher magnification shows the plated dense matted deposits (Fig. 3c, arrow) that individual fibers fuse longitudinally (star). Where PRP is exposed to iron followed by a 3-min deferoxamine exposure (Figs 2d

Fig. 2
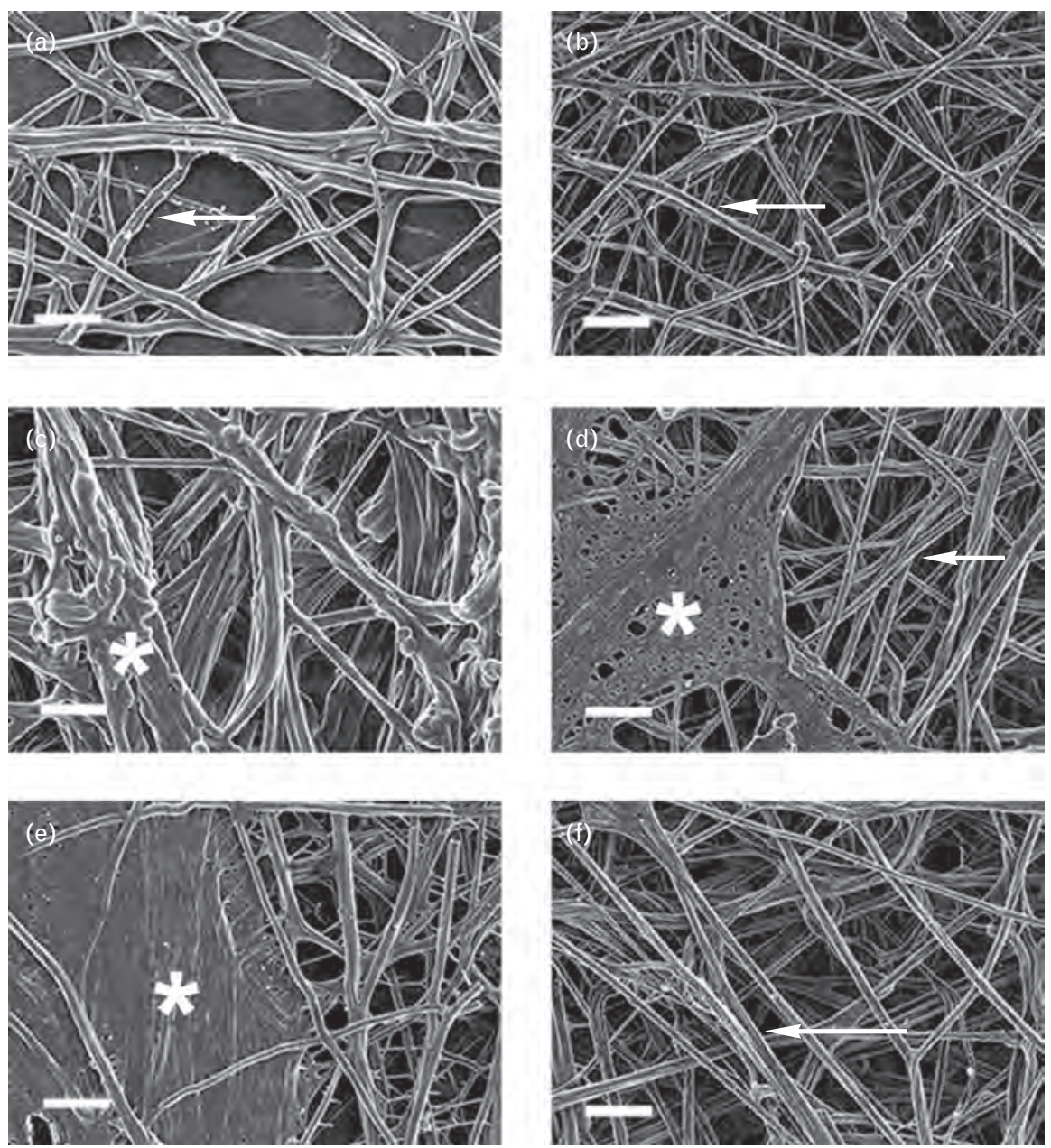

Scanning electron microphotographs of platelet-rich plasma (PRP) after exposure to $\mathrm{FeCl}_{3}$ and/and deferoxamine at low magnification followed by addition of thrombin before washing and fixing in all experiments to create extensive fibrin network. (a) $1 \mathrm{ml} \mathrm{PRP}+10 \mu \mathrm{l} \mathrm{PBS}+10 \mu \mathrm{l}$ double-distilled water (combination 1, C1); (b) $1 \mathrm{ml} \mathrm{PRP}+10 \mu \mathrm{PBS}+10 \mu \mathrm{l}$ of a $100 \mathrm{mmol} / /$ deferoxamine (C2); (c) $1 \mathrm{ml} \mathrm{PRP}+10 \mu \mathrm{l}$ of a $1 \mathrm{mmol} / \mathrm{FeCl}{ }_{3}$, incubate $3 \mathrm{~min},(\mathrm{C} 3) ;$ (d) $1 \mathrm{ml} \mathrm{PRP}+10 \mu \mathrm{l}$ of a $1 \mathrm{mmol} / / \mathrm{FeCl}_{3}$, add $10 \mu \mathrm{l} 100 \mathrm{mmol} / \mathrm{l}$ deferoxamine and incubate for $3 \mathrm{~min}(\mathrm{C} 4) ;(\mathrm{e}) 1 \mathrm{ml} \mathrm{PRP}+10 \mu \mathrm{l}$ of a $1 \mathrm{mmol} / / \mathrm{FeCl}_{3}$, incubate $3 \mathrm{~min}$, incubate for $1 \mathrm{~h}$ at room temperature (C5); (f) $1 \mathrm{ml} \mathrm{PRP}+10 \mu \mathrm{l}$ of a $1 \mathrm{mmol} / \mathrm{l} \mathrm{FeCl}$; incubate $3 \mathrm{~min}$, then add $10 \mu \mathrm{l}$ of $100 \mathrm{mmol} / \mathrm{l}$ deferoxamine and incubate for $1 \mathrm{~h}$ at room temperature (C6). Machine magnification is $40000 \times$ and scale $=1 \mu \mathrm{m}$. 

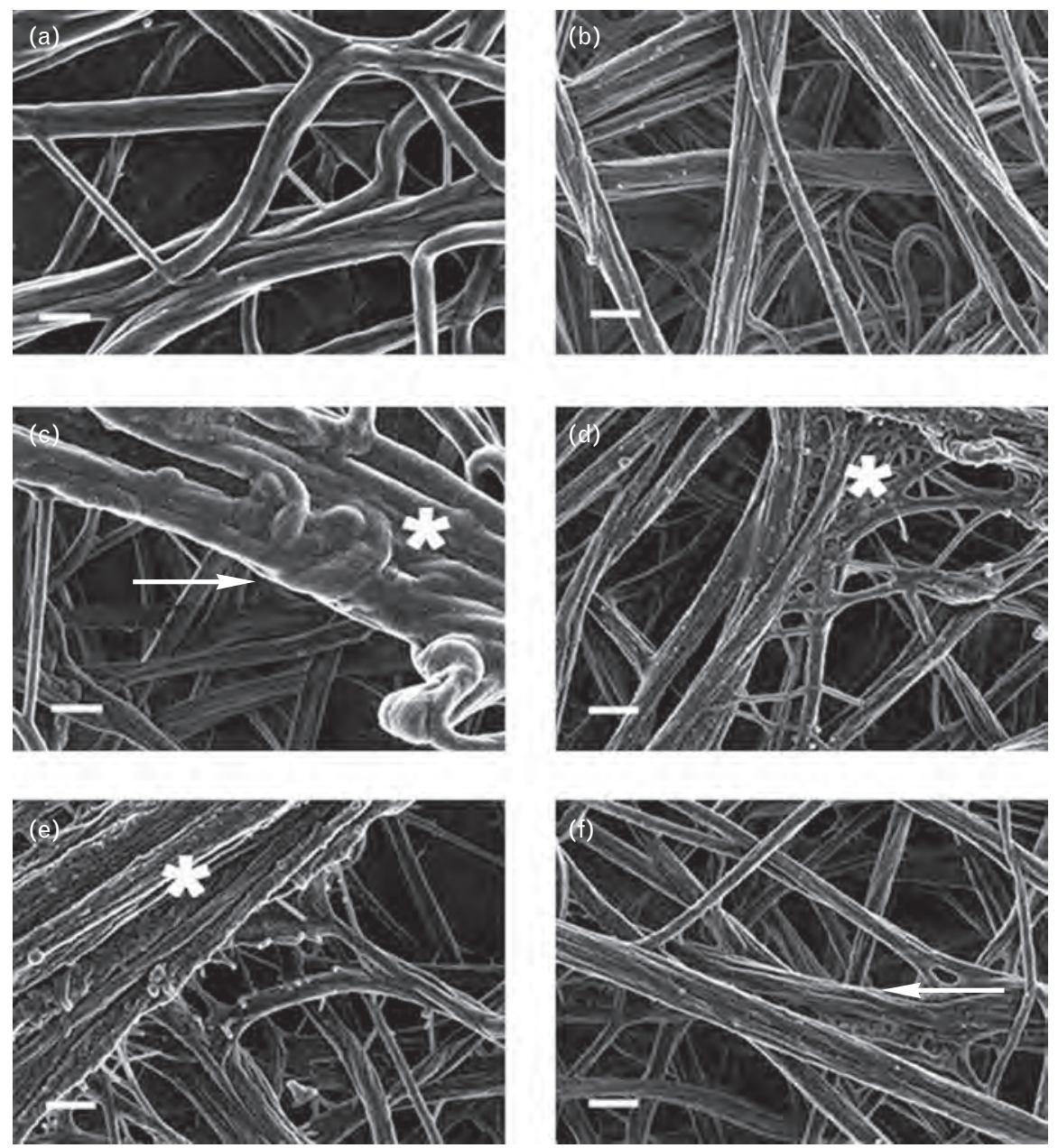

Scanning electron microphotographs of platelet-rich plasma (PRP) after exposure to $\mathrm{FeCl}_{3}$ and/or deferoxamine at high magnification followed by addition of thrombin before washing and fixing in all experiments to create extensive fibrin network. (a) $1 \mathrm{ml} \mathrm{PRP}+10 \mu / \mathrm{PBS}+10 \mu \mathrm{l}$ double-distilled water (combination 1, C1); (b) $1 \mathrm{ml} \mathrm{PRP}+10 \mu \mathrm{l} \mathrm{PBS}+10 \mu \mathrm{l}$ of a $100 \mathrm{mmol} / \mathrm{l}$ deferoxamine (C2); (c) $1 \mathrm{ml} \mathrm{PRP}+10 \mu \mathrm{l}$ of a $1 \mathrm{mmol} / \mathrm{l} \mathrm{FeCl}$, incubate $3 \mathrm{~min},(\mathrm{C} 3) ;(\mathrm{d}) 1 \mathrm{ml} \mathrm{PRP}+10 \mu \mathrm{l}$ of a $1 \mathrm{mmol} / / \mathrm{FeCl}_{3}$, add $10 \mu \mathrm{l} 100 \mathrm{mmol} / /$ deferoxamine and incubate for $3 \mathrm{~min}(\mathrm{C} 4) ;(\mathrm{e}) 1 \mathrm{ml}$ PRP $+10 \mu \mathrm{l}$ of a $1 \mathrm{mmol} / / \mathrm{FeCl}_{3}$, incubate for $3 \mathrm{~min}$, incubate for $1 \mathrm{~h}$ at room temperature (C5); (f) $1 \mathrm{ml} \mathrm{PRP}+10 \mu \mathrm{l}$ of a $1 \mathrm{mmol} / / \mathrm{FeCl}$; incubate $3 \mathrm{~min}$, then add $10 \mu \mathrm{l} 100 \mathrm{mmol} / \mathrm{l}$ deferoxamine and incubate for $1 \mathrm{~h}$ at room temperature (C6). Machine magnification is $100000 \times$ and scale $=300 \mathrm{~nm}$.

and 3d), the matted plates seem to be less dense (star on both figures) and the individual fibers are no longer fused longitudinally (Fig. 3d, arrow).

We also investigated the effect of time on the fibrin formation. Figs 2e and 3e show PRP exposed to iron for $1 \mathrm{~h}$ followed by net creation by adding thrombin. This experiment was done at room temperature and in a capped Eppendorf tube. Prolonged iron exposure caused the fibrin fibers to form a much thicker homogenous dense matted deposit, wherein nearly no individual fibers are visible at the lower magnification (Fig. 3e, star). However, at the higher magnification (Fig. 4e, star), individual, longitudinally fused fibers can still be seen. When deferoxamine is added $3 \mathrm{~min}$ after the iron was added to PRP and this mixture was also left for $1 \mathrm{~h}$ in a capped Eppendorf tube at room temperature, before thrombin was added (Figs $2 \mathrm{f}$ and $3 \mathrm{f}$ ), the fibrin nets are not as matted as without the iron chelator, and individual fibrin fibers are again visible, although not fully restored as is seen in a typical healthy fibrin fiber network (arrows).

\section{Discussion}

The primary finding of the present investigation was that the coagulation kinetic and ultrastructural changes induced by clinically encountered free iron concentrations were partially attenuated by chelation with deferoxamine. This finding is critical, as binding without generation of radical species with consequent conformational changes in fibrinogen structure can now be entertained as an important mechanism by which iron 
mediates hypercoagulability. As we previously noted, radical species typically irreversibly decrease fibrinogen function in an irreversible fashion [13,14], and our experiments demonstrated reversibility secondary to iron chelation and presumed unbinding of iron from fibrinogen. The residual effects of iron after chelation may be secondary to incomplete removal of exogenously added iron or some other iron-mediated effect on fibrinogen that is not reversible, or both. The extent of return of coagulation function following chelation of plasma with $10 \mu \mathrm{mol} / \mathrm{I} \mathrm{FeCl}_{3}$ addition was equivalent to a $\mathrm{R}$ value similar to that associated with plasma exposed to $2 \mu \mathrm{mol} / 1$ $\mathrm{FeCl}_{3}$ (compare Fig. 1 and Table $1 \mathrm{R}$ values). In sum, although complete reversal of iron-mediated changes in thrombelastographic and SEM-derived data was not achieved, partial reversal with chelation strongly supports iron binding as a significant mechanism mediating hypercoagulability.

Given this new paradigm, a reexamination of both thrombophilic states associated with iron overload is indicated. Using deferoxamine-mediated chelation, appropriate temperature, and sufficient incubation time, it will be potentially possible to assess the impact of iron with thrombelastography, thromboelastimetry, or SEM. Thus, as reviewed [1], the role of ferritin and free iron excess in chronic diseases such as diabetes mellitus, rheumatoid arthritis, or perhaps cancer [19] can be assessed. Perhaps the degree of iron-specific hypercoagulability could be correlated with clinical disease, and in turn, such diagnostics could be used to assess the effectiveness of therapy targeted at diminishing circulating iron concentrations or interventions that diminish inflammatory processes that result in iron overload. The utility of such a diagnostic evaluation of iron-mediated hypercoagulability in research or clinical settings will be defined in future investigations.

In conclusion, using thrombelastographic and SEM approaches, we have determined that reversible iron binding to presumably fibrinogen is an important mechanism by which iron causes hypercoagulability. Additional study will be required to further determine whether residual binding or other iron-mediated effects are responsible for residual hypercoagulability observed after chelation.

\section{Acknowledgements}

Grant support: This investigation was supported by the Departments of Anesthesiology and Physiology.

\section{Conflicts of interest}

The authors declare no conflicts of interest.

\section{References}

1 Kell DB, Pretorius E. Serum ferritin is an important inflammatory disease marker, as it is mainly a leakage product from damaged cells. Metallomics 2014; 6:748-773. doi: 10.1039/c3mt00347g.

2 Lipinski B, Pretorius E. Novel pathway of iron-induced blood coagulation: implications for diabetes mellitus and its complications. Pol Arch Med Wewn 2012; 122:115-122.

3 Lipinski B, Pretorius E, Oberholzer HM, van der Spuy WJ. Iron enhances generation of fibrin fibers in human blood: implications for pathogenesis of stroke. Microsc Res Tech 2012; 75:1185-1190.

4 Pretorius E, Vermeulen N, Bester J, Lipinski B. Novel use of scanning electron microscopy for detection of iron-induced morphological changes in human blood. Microsc Res Tech 2013; 76:268-271.

5 Lipinski B, Pretorius E. Iron-induced fibrin in cardiovascular disease. Curr Neurovasc Res 2013; 10:269-274.

6 Pretorius E, Lipinski B. Differences in morphology of fibrin clots induced with thrombin and ferric ions and its pathophysiological consequences. Heart Lung Circ 2013; 22:447-449.

7 Pretorius E, Oberholzer HM, van der Spuy WJ, Swanepoel AC, Soma P. Qualitative scanning electron microscopy analysis of fibrin networks and platelet abnormalities in diabetes. Blood Coagul Fibrinolysis 2011; 22:463-467.

8 Pretorius E, Oberholzer HM, van der Spuy WJ, Swanepoel AC, Soma P. Scanning electron microscopy of fibrin networks in rheumatoid arthritis: a qualitative analysis. Rheumatol Int 2012; 32:1611-1615.

9 Lipinski B. Modification of fibrin structure as a possible cause of thrombolytic resistance. J Thromb Thrombolysis 2010; 29:296298.

10 Lipinski B, Pretorius E. Hydroxyl radical-modified fibrinogen as a marker of thrombosis: the role of iron. Hematology 2012; 17:241-247.

11 Pretorius E, Vermeulen N, Bester J, Lipinski B, Kell DB. A novel method for assessing the role of iron and its functional chelation in fibrin fibril formation: the use of scanning electron microscopy. Toxicol Mech Methods 2013; 23:352-359.

12 Pretorius E, Bester J, Vermeulen N, Lipinski B, Gericke GS, Kell DB. Profound morphological changes in the erythrocytes and fibrin networks of patients with hemochromatosis or with hyperferritinemia, and their normalization by iron chelators and other agents. PLoS One 2014; 9:e85271.

13 Shacter E, Williams JA, Levine RL. Oxidative modification of fibrinogen inhibits thrombin-catalyzed clot formation. Free Radic Biol Med 1995; 18:815-821.

14 Martinez M, Weisel JW, Ischiropoulos $\mathrm{H}$. Functional impact of oxidative posttranslational modifications on fibrinogen and fibrin clots. Free Radic Biol Med 2013; 65:411-418.

15 Yeum KJ, Russell RM, Krinsky NI, Aldini G. Biomarkers of antioxidant capacity in the hydrophilic and lipophilic compartments of human plasma. Arch Biochem Biophys 2004; 430:97-103.

16 Orino K. Functional binding analysis of human fibrinogen as an iron- and heme-binding protein. Biometals 2013; 26:789-794.

17 Nielsen VG, Cohen JB, Malayaman SN, Nowak M, Vosseller K. Fibrinogen is a heme-associated, carbon monoxide sensing molecule: a preliminary report. Blood Coagul Fibrinolysis 2011; 22:443-447.

18 Nielsen VG, Pretorius E. Iron and carbon monoxide enhance coagulation and attenuate fibrinolysis by different mechanisms. Blood Coagul Fibrinolysis 2014; in press, PMID: 24732176.

19 Panis C, Victorino VJ, Herrera ACSA, Freitas LF, De Rossi T, Campos FC et al. Differential oxidative status and immune characterization of the early and advanced stages of human breast cancer. Breast Cancer Res Treat 2012; 133:881-888. 